\title{
Effectiveness of ultrasonography and nerve conduction studies in the diagnosing of carpal tunnel syndrome: clinical trial on accuracy
}

Benedito Felipe Rabay Pimentel ${ }^{1 *}$, Flávio Faloppa ${ }^{2}$, Marcel Jun Sugawara Tamaoki ${ }^{2}$ and João Carlos Belloti ${ }^{2}$

\begin{abstract}
Background: The aim of this study was to evaluate the effectiveness of two diagnostic tests routinely used for diagnosing carpal tunnel syndrome (CTS) —ultrasonography (US) and nerve conduction studies (NCS) — by comparing their accuracy based on surgical results, with the remission of paresthesia as the reference standard.

Methods: We enrolled 115 patients, all of the female gender with a high probability of a clinical diagnosis of CTS. All patients underwent US and NCS for a diagnosis and subsequent surgical treatment. As a primary outcome, the accuracy of the US and NCS diagnoses was measured by comparing their diagnoses compared with those determined by the surgical outcomes. Their accuracy was secondarily evaluated based on before and after scores of the Boston Carpal Tunnel Questionnaire (BCTQ).
\end{abstract}

Results: Overall, 104 patients (90.4\%) were diagnosed with CTS by the surgical reference standard, 97 (84.3\%) by NCS, and 90 (78.3\%) by US. The concordance of NCS and surgical treatment $(p<0.001$; kappa $=0.648)$ was superior to that of US and surgical treatment $(p<0.001$; kappa $=0.423)$. The sensitivity and specificity of US and NCS were similar $(p=1.000$ and $p=0.152$, respectively: McNemar's test). The BCTQ scores were lower after surgery in patients diagnosed by both US and NCS $(p<0.001$ and $p<0.001$, respectively: analysis of variance).

Conclusions: US and NCS effectively diagnosed CTS with good sensitivity but were not effective enough to rule out a suspicion of CTS.

Trial registration: This study was registered at September, 10 th, 2015, and the registration number was NCT02553811.

Keywords: Carpal tunnel syndrome, Diagnostic accuracy, Diagnostic practices, Clinical diagnosis, Surgical treatment, Ultrasonography, Ultrasound, Nerve conduction studies, Electrodiagnostic testing, Electromyograph

\section{Background}

Carpal tunnel syndrome (CTS), characterized by compression of the median nerve at the wrist level, is the most common compressive neuropathy of the upper limb $[1,2]$. Ultrasonography (US) and nerve conduction studies (NCS) are diagnostic tests routinely used to confirm the diagnosis of CTS $[3,4]$. As the parameters of

\footnotetext{
* Correspondence: befecil@gmail.com

${ }^{1}$ Division of Hand Surgery and Upper Limb, Discipline of Orthopaedics and Traumatology, Paraiba Valley Regional Hospital and Taubaté University Hospital, University of Taubaté, 239 Francisco de Barros, Taubaté, São Paulo zip code 12020-230, Brazil

Full list of author information is available at the end of the article
}

US and NCS have not been standardization for this diagnosis, and the cutoff point for a CTS diagnosis has not been established, the diagnostic accuracy values for both tests vary widely in the literature. These variations could be related to different study designs, sample sizes, and reference standards that do not reflect routine clinical practice $[1,2]$. Thus, the diagnosis of CTS is inconsistent and controversial, with no universally accepted reference standard $[5,6]$.

Well-designed primary CTS studies of methodological quality sufficient to guide diagnostic practices are uncommon and challenging [7-10]. Hence, we propose a strategy for diagnosing CTS in routine clinical practice.

(c) The Author(s). 2018 Open Access This article is distributed under the terms of the Creative Commons Attribution 4.0 International License (http://creativecommons.org/licenses/by/4.0/) which permits unrestricted use, distribution, and reproduction in any medium, provided you give appropriate credit to the original author(s) and the source, provide a link to the Creative Commons license, and indicate if changes were made. The Creative Commons Public Domain Dedication waiver (http://creativecommons.org/publicdomain/zero/1.0/) applies to the data made available in this article, unless otherwise stated. 
It includes a methodological resource, based on an algorithm, that could help obtain answers to the question of what is the best pathway to an accurate diagnosis of CTS. This study aimed to evaluate the effectiveness of two diagnostic tests routinely used for diagnosing CTS by comparing the accuracy of US and NCS with the results of the surgical treatment for the CTS. Remission of paresthesia following surgery was the reference standard.

\section{Methods}

Ethical approval, registration, guidelines and study design The ethics and research committees of Federal University of São Paulo/Paulista School of Medicine, São Paulo, Brazil (approval No. 244468) and Paraiba Valley Regional Hospital and Taubaté University Hospital, University of Taubaté, Taubaté, Brazil (No. 009/13) approved this study. It was registered in "ClinicalTrials.gov" (No. NCT02553811) and followed the recommendations of the STARD [11]. It is a primary, longitudinal, prospective clinical trial to determine accuracy performed at a single center.

\section{Participants and eligibility criteria}

Initially were evaluated 173 participants with a clinical suspicion of CTS. All participants who agreed to participate in this study signed the informed consent form and underwent an initial clinical evaluation by the same specialist in hand surgery. According to the sample calculation, it was necessary to include a total of 115 eligible patients.

\section{Probability of the clinical diagnosis: CTS-6 model}

The CTS-6 [5], represents a logistic regression model that estimates the diagnostic probability of CTS. "See Additional file 1: Table S6". A total score $\geq 12$ was considered to indicate a high probability of a clinical diagnosis of CTS. There are six criteria for the probability of a clinical diagnosis (CTS-6), with their respective scores evaluated based clinical history and physical examination on the patient's initial clinical evaluation.

1. Paresthesia: in the territory of distribution of the median nerve of the affected hand during any period of the day and when performing manual tasks (3.5 points)

2. Night paresthesia: in the territory of distribution of the median nerve of the affected hand during sleep or in the morning upon awakening (4.0 points)

3. Weakness and hypotrophy or atrophy of the tenar musculature: loss of strength needed to grasp objects, dropping them; evaluated by testing the tenar musculature with the thumb in opposition (5.0 points)

4. Tinel test: performed by applying digital percussion in the anatomical path of the median nerve at wrist level; test is positive when the patient reports a sensation of "shock" at the percussion site that irradiates to the territory of distribution of the median nerve in the affected hand ( 4.0 points)

5. Phalen test: performed by the positioning the wrist and elbow at $90^{\circ}$ of flexion for 30-60 s; test is positive when the patient reports the onset or exacerbation of paresthesia in the territory of distribution of the median nerve of the affected hand (5.0 points)

6. Discrimination of sensory stimuli applied between two points: performed by applying at least 10 cutaneous sensorial stimuli using a discriminator instrument positioned longitudinally in the digital pulp of the indicators, not in direct view of the patient; test is positive when the patient does not identify at least 7 of the 10 discriminator stimuli placed at intervals of $\leq 6 \mathrm{~mm}$ (4.5 points)

\section{Inclusion and exclusion criteria}

Inclusion criteria were a CTS- 6 score of $\geq 12$ points, female gender, aged 40-80 years, unilateral or bilateral

Table 1 Distribution of patients by US and NCS results in relation to results of surgical treatment

\begin{tabular}{|c|c|c|c|c|c|c|}
\hline \multirow[t]{3}{*}{ Parameter } & \multicolumn{4}{|c|}{ Surgical treatment } & \multirow{2}{*}{\multicolumn{2}{|c|}{ Total }} \\
\hline & \multicolumn{2}{|c|}{ No remission of paresthesia (CTS absent) } & \multicolumn{2}{|c|}{ Remission of paresthesia (CTS present) } & & \\
\hline & $\bar{N}$ & $\%$ & $n$ & $\%$ & $\mathrm{~N}$ & $\%$ \\
\hline US & 11 & 9.6 & 104 & 90.4 & 115 & 100.0 \\
\hline CSA $<10 \mathrm{~mm}^{2}$ (CTS absent) & 9 & 7.8 & 16 & 13.9 & 25 & 21.7 \\
\hline CSA $\geq 10 \mathrm{~mm}^{2}$ (CTS present) & 2 & 1.7 & 88 & 76.5 & 90 & 78.3 \\
\hline NCS & 11 & 9.6 & 104 & 90.4 & 115 & 100.0 \\
\hline $\mathrm{SCV} \geq 50 \mathrm{~m} / \mathrm{s}$ and $\mathrm{DML}<4.2 \mathrm{~ms}$ (CTS absent) & 10 & 8.7 & 8 & 7.0 & 18 & 15.7 \\
\hline $\mathrm{SCV}<50 \mathrm{~m} / \mathrm{s}$ and $\mathrm{DML} \geq 4.2 \mathrm{~ms}$ (CTS present) & 1 & 0.9 & 96 & 83.5 & 97 & 84.3 \\
\hline
\end{tabular}

$n=115$ patients

Results are given as the total percent

CSA cross sectional area, CTS carpal tunnel syndrome, NCS nerve conduction studies, DML distal motor latency, US ultrasonography, SCV sensory conduction velocity 
Table 2 Observed and expected concordances and Kappa coefficient for the comparisons between US, NCS and surgery

\begin{tabular}{|c|c|c|c|c|c|c|}
\hline Comparison & Observed concordance & Expected concordance & Kappa coefficient & Standard error & z & $p$ \\
\hline US vs. surgery & $84.4 \%$ & $72.9 \%$ & 0.423 & 0.083 & 5.08 & $<0.001$ \\
\hline NCS vs. surgery & $92.2 \%$ & $77.8 \%$ & 0.648 & 0.090 & 7.22 & $<0.001$ \\
\hline US vs. NCS & $76.5 \%$ & $69.4 \%$ & 0.232 & 0.091 & 2.54 & 0.006 \\
\hline
\end{tabular}

NCS nerve conduction studies, US ultrasonography

There were 115 subjects in each comparison group

involvement (only a more symptomatic hand was considered for inclusion), previous conservative treatment for CTS without clinical improvement. Exclusion criteria were the presence of cervical radiculopathy, thoracic outlet syndrome, pronator syndrome; a history of previous surgical release of the carpal tunnel, with sequelae of fracture of the wrist; a CTS- 6 score of $\leq 12$ points; lack of compliance at any stage of the study.

\section{Diagnostic interventions}

After the initial physical examination, eligible patients underwent both US and NCS. These diagnostic interventions were performed in our institution, consecutively and randomly on different days by the same professional experts who were specialized and experienced with US and NCS. They were unaware of the clinical situation of the patients at the time of the examination.

\section{US}

All US evaluations were performed on the same equipment (model M2540A; Philips Healthcare, Bothell, WA USA) with high resolution and broadband linear transducers, 4-6 MHz and 9-13 MHz. The US examination technique consisted of positioning the patient comfortably: sitting with the affected forearm in a supine position in slight flexion and supported on the examination table. The wrist is in neutral position and the fingers in extension [12]. The objective of US was to determine the cross-sectional area (CSA) of the median nerve at the proximal limit ("in let") of the carpal tunnel by direct measurement. To evaluate the diagnostic accuracy of US, an CSA value $\geq 10$. $0 \mathrm{~mm}^{2}$ was the cutoff point to confirm a diagnosis of CTS [3, 12-15].

\section{NCS}

All NCS was performed on the same equipment (model MEB 9400 K, two channels; Nihon Kohden, Tokyo, Japan). The NCS technique consisted of positioning the patient comfortably in a horizontal dorsal decubitus position with the upper limbs positioned at rest along the body and prepared for a comparative assessment of the muscular groups and the median, ulnar and radial nerves, to exclude other conditions and differential diagnoses [16-20]. The temperature of the upper limb to be examined was acclimatized at $32{ }^{\circ} \mathrm{C}$. The age and temperature of the patients were considered in the diagnostic parameters of CTS by NCS evaluation [16]. The objective of the NCS was to determine the sensory conduction velocity $(\mathrm{SCV})$ of the median nerve in the third finger-wrist segment for a length of $13 \mathrm{~cm}$ and the distal motor latency (DML) of the median nerve from the wrist to the tenar eminence. To evaluate the diagnostic accuracy of NCS, the cutoff values to confirm a

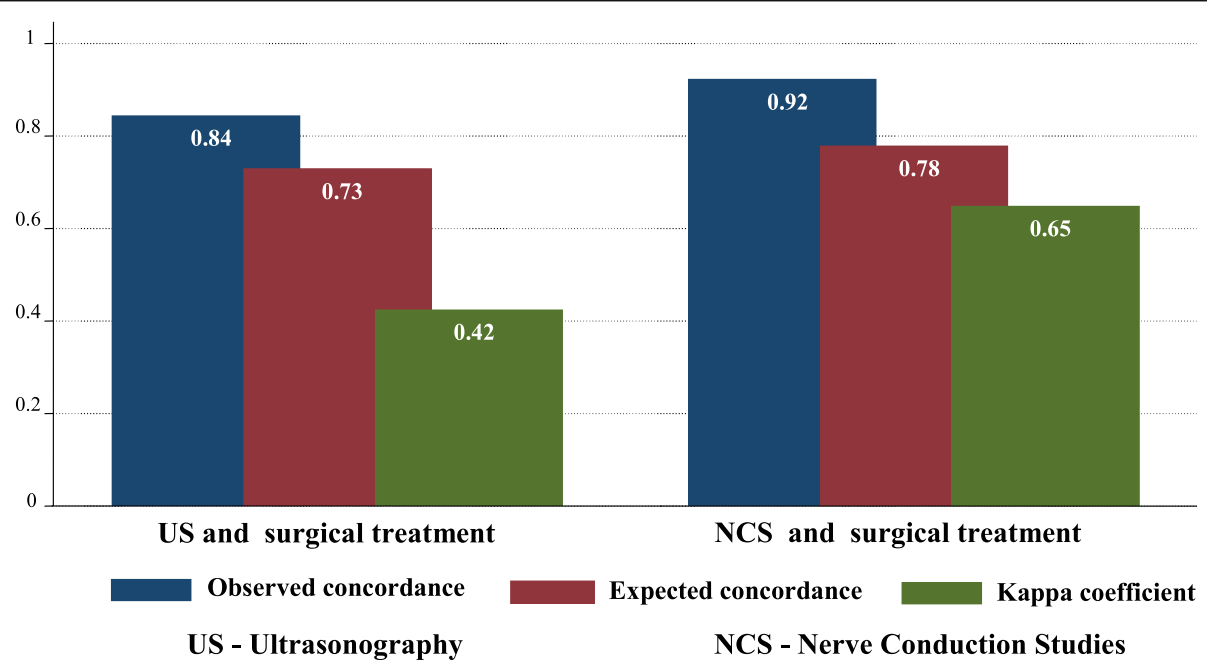

Fig. 1 Comparison between observed, expected concordances and Kappa coefficient of the US and NCS 
diagnosis of CTS were $<50 \mathrm{~m} / \mathrm{s}$ for SCV and $\geq 4.2 \mathrm{~ms}$ for DML [3, 16-20].

\section{Evaluation of the performance of diagnostic tests Surgical treatment}

After US and NCS had been performed, the patients were forwarded and underwent to surgical treatment in our institution, by one and the same surgeon. All patients underwent intravenous regional Bier block anesthesia [21]. The surgical technique used was classic open release through a palmar longitudinal incision about $2 \mathrm{~cm}$ in length that did not extend proximally beyond the distal flexion fold of the wrist or distally beyond the Kaplan line [22]. The patients were sent home on the same day and were followed through the fourth postoperative month [23].

\section{Primary outcome}

Paresthesia remission after surgical treatment was considered the reference standard for diagnosing CTS. Patients with CTS who achieved paresthesia remission postoperatively were considered truly affected by CTS, and patients who did not experience remission were considered not to have CTS [8]. The accuracy of the two preoperative diagnostics methods was measured the evaluating the US and NCS results (positive or negative) relative to the results of the surgery (remission/no remission of paresthesia) $[9,10]$.

\section{Secondary outcome}

The Boston Carpal Tunnel Questionnaire (BCTQ) is a disease-specific (CTS) questionnaire that is self-

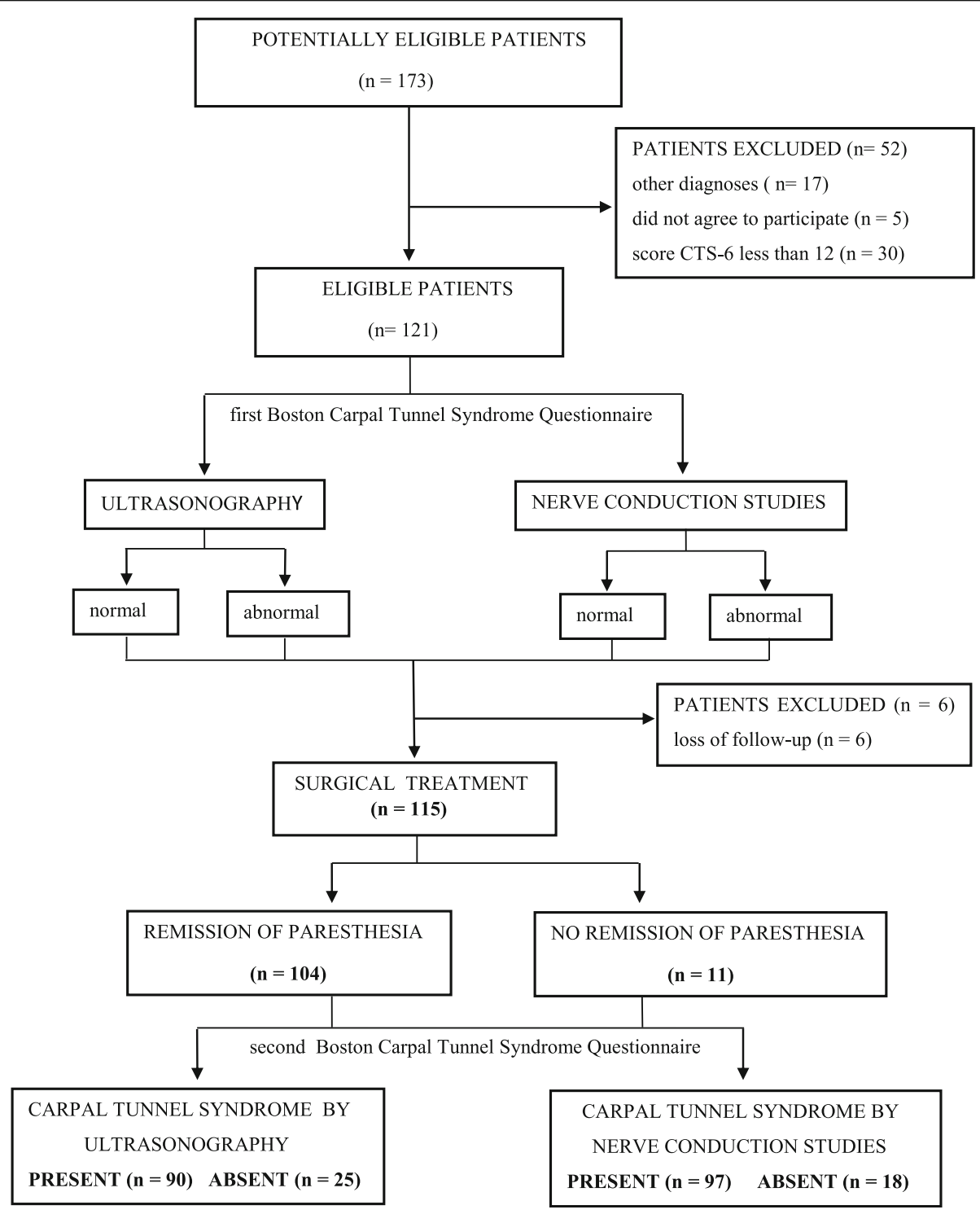

Fig. 2 Flowchart of the diagnostic intervention results 
administered and has been translated into the portuguese language and validated, which evaluates two components: a scale of severity of symptoms and a scale of functional status [24, 25]. All patients in this study responded to two BCTQs: the first after the initial clinical evaluation and the second at the end of the fourth month of postoperative follow-up.

\section{Statistical analysis}

The categorical variables were presented as relative and absolute frequencies, and numerical variables were presented as a measures summary. The evaluation of the observed and expected concordance between US and NCS and the surgical treatment were performed using the kappa coefficient. The accuracy of the US and NCS relative to the paresthesia remission after surgical treatment (reference standard) was evaluated using the McNemar. Sensitivity, specificity, positive and negative predictive values, and positive and negative likelihood ratios were analyzed by statistical calculations of expected values and obtained in a $2 \times 2$ contingency table. The evolution of the BCTQ score by moments of evaluation and diagnostic results was evaluated using analysis of variance with repeated measures. For all statistical tests, a significance level of 5\% was adopted [26]. The statistical package SPSS 20.0 (IBM Corp., Armonk, NY, USA) and Stata12 (Stata Corp., College Station, TX, USA) software was used for the analyses.

The statistical sampling was performed considering a $20 \%$ difference between the sensitivity of the NCS and US diagnostic tests using the McNemar test, with a statistical power of $84.0 \%$ and a significance level of $5 \%$. For this calculation, we assumed as percentage of total concordance the value of $60 \%$ and a prevalence of $80 \%$ for STC, requiring a total sample of 115 patients [26]. Statistical software PASS 14 (Power Analysis and Sample Size System; NCSS, https://www.ncss.com) was used.

\section{Results}

\section{Study population}

A total of 115 women were evaluated (average age \pm SD $52.9 \pm 9.1$ years, range $40-79$ years, median 52 years). The average \pm SD disease duration was $4.0 \pm 3.2$ years, range 1-20 years, median 3 years. "See Additional file 2: Table S7".

\section{Concordance between the diagnoses}

Table 1 shows the total percentages of diagnoses of CTS by the US and NCS relative to the total percentage of diagnoses according to the surgical results (based on remission, or not, of paresthesia). "See Additional file 3: Table S8".

As seen in Table 2, there was moderate concordance between US and the surgical outcomes $(p<0.001$, kappa $=0.423$ ), good concordance between NCS and the surgical outcomes $(\mathrm{p}<0.001$, kappa $=0.648)$, and reasonable concordance between US and NCS $(p=0.006$, kappa $=0$. 232) (Fig. 1).

\section{Accuracy of diagnostic tests}

The results of the diagnostic interventions are summarized in Fig. 2.

The sensitivity, specificity, and positive predictive values for US ( $p=1.000$, McNemar test $)$ and NCS ( $p=0$. 152 , McNemar test) were similar, with no statistical differences between the two diagnostic methods (Fig. 3). The negative predictive values, however, were lower than expected for both US and NCS. "Additional file 4: Table

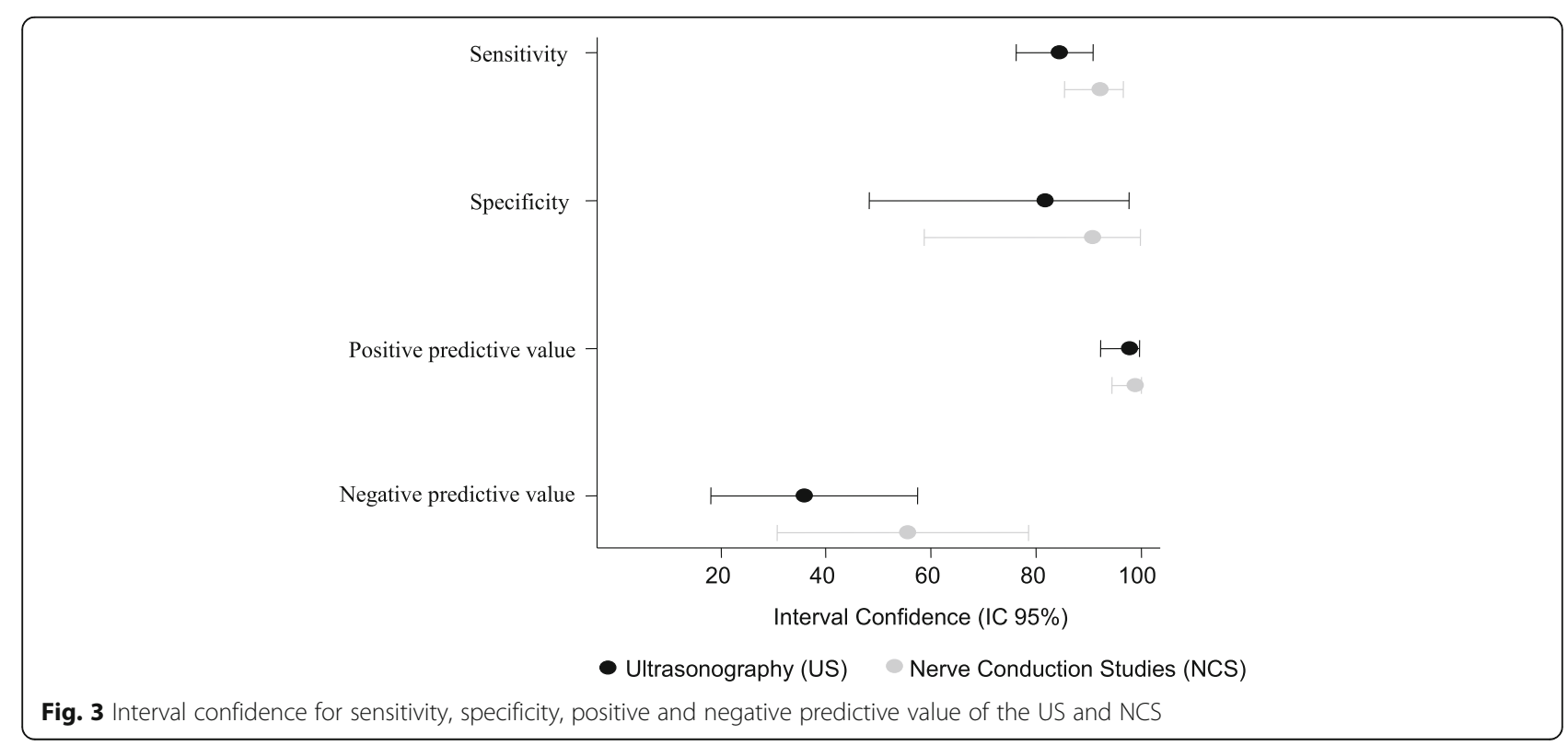


S9, Additional file 5: Table S10, Additional file 6: Table S11, Additional file 7: Table S12". The positive and negative likelihood values were accurate and associated with few false-positive and false-negative results for the cutoff point considered and according to the reference standard used (Figs. 4 and 5). "Additional file 8: Table S13 and Additional file 9: Table S14 respectively, shows this with more details". The diagnostic accuracies for US and NCS, according to the statistical parameters of this study, are summarized in Table 3.

\section{Assessment of severity of symptoms and functional status}

According to Tables 4 and 5, the mean symptom severity score was reduced by 1.8 points and the functional status score by 1.6 points on the second BCTQ, applied 4 months after surgery in patients with a CTS diagnosis (Figs. 6, 7, 8 and 9).

\section{Discussion}

Well-designed studies that have focused on the diagnosis of CTS are uncommon. The deficiencies in the design of studies involving clinical and complementary tests for CTS are associated with a super-estimation of the performance of these diagnostic tests and the lack of a universally accepted reference standard for diagnosing CTS [6, 8-10]. Most CTS diagnostic accuracy studies were unlikely to report results that are applicable in clinical practice $[1,27]$. The current study design followed an algorithm based on evaluating an actual clinical practice routine for diagnosing CTS: from the consecutive and random eligibility of patients based on a high probability of a clinical diagnosis of

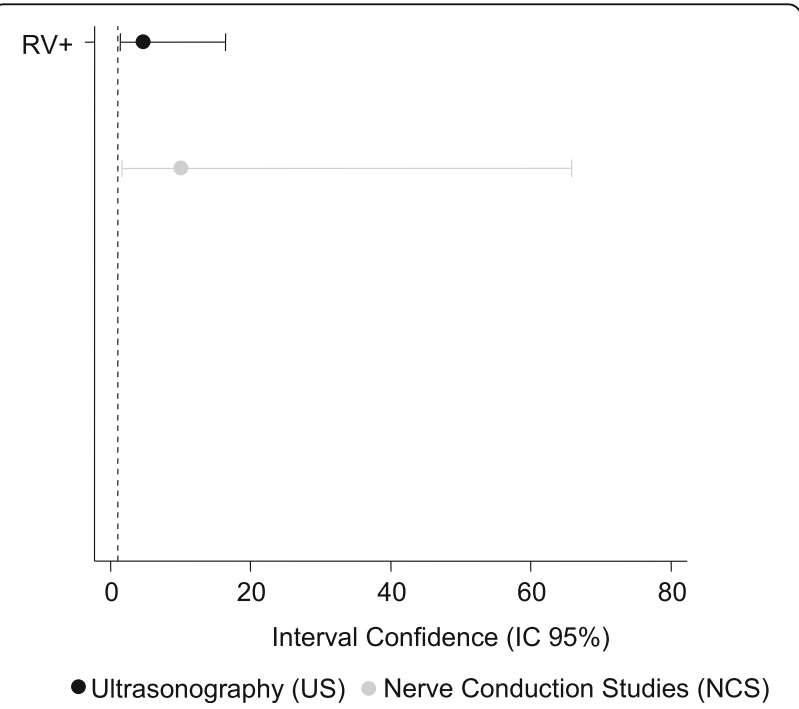

Fig. 4 Confidence Interval for positive likelihood ratios (RV+) of the US and NCS

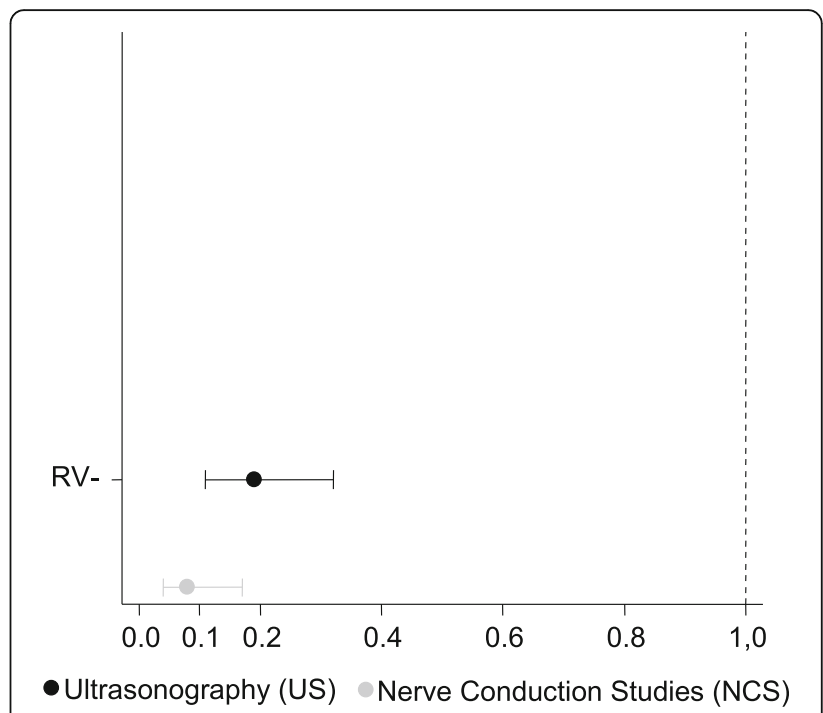

Fig. 5 Confidence Interval for negative likelihood ratios (RV-) of the US and NCS

CTS, confirmed (or not) by US and NCS-performed such that the examiners were unaware of the clinical condition of the patients and the results of the concurrent complementary examination treatment follow-up and its clinical outcomes. To ensure good diagnostic accuracy it is important that the estimates provided by a diagnostic test reflect its good performance in clinical practice [1]. The remission of paresthesia (reference standard) after surgical treatment was used in this study to evaluate the effectiveness and performance of the diagnosis of CTS by the US and NCS [3]. The classical open approach is considered a definitive surgical treatment for CTS with good results in 75 to $90 \%$ of patients [23]. In this study, $90.4 \%$ of the 115 operated patients obtained remission of paresthesia with four months pos operative, while in another study $78.9 \%$ of the 113 operated patients obtained remission of paresthesia with ten years pos operative by same surgical technique. [28]. As for the $9.6 \%$ of operated patients who did not obtain remission of paresthesia with surgical treatment in our study, it can be attributed to proximal compressions of the median nerve, double cervical

Table 3 Comparison of US and NCS: statistical values

\begin{tabular}{lll}
\hline Statistical parameter & US & NCS \\
\hline Sensitivity(\%) & $84.6(76.2-90.9)$ & $92.3(85.4-96.6)$ \\
Specificity(\%) & $81.8(48.2-97.7)$ & $90.9(58.7-99.8)$ \\
Positive predictive value(\%) & $97.8(92.2-99.7)$ & $99.0(94.4-100.0)$ \\
Negative predictive value(\%) & $36.0(18.0-57.5)$ & $55.6(30.8-78.5)$ \\
Positive likelihood ratio(\%) & $4.7(1.3-16.4)$ & $10.2(1.6-65.9)$ \\
Negative likelihoodratio(\%) & $0.2(0.1-1.3)$ & $0.1(0-0.2)$ \\
\hline
\end{tabular}

NCS nerve conduction studies, US ultrasonography 
Table 4 BCTQ scores for severity scale of symptoms relative to CTS diagnosis by US and NCS

\begin{tabular}{llll}
\hline Parameter & After treatment & Before treatment & Difference between after and before treatment \\
\hline US & & & \\
$\quad \mathrm{CSA} \geq 10 \mathrm{~mm}^{2}$ (presence) & $1.7(0.7)$ & $3.5(0.7)$ & $-1.8(0.9)$ \\
$\mathrm{CSA}<10 \mathrm{~mm}^{2}$ (absence) & $1.9(0.8)$ & $3.7(0.8)$ & $-1.8(1.0)$ \\
$\mathrm{NCS}$ & & & $-1.8(0.9)$ \\
$\mathrm{SCV}<50 \mathrm{~m} / \mathrm{s}$ and DML $\geq 4.2 \mathrm{~ms}$ (presence) & $1.7(0.7)$ & $3.5(0.7)$ & $-1.6(1.0)$ \\
$\mathrm{SCV} \geq 50 \mathrm{~m} / \mathrm{s}$ and $\mathrm{DML}<4.2 \mathrm{~ms}$ (absence) & $2.1(0.9)$ & $3.7(0.8)$ & \\
\hline
\end{tabular}

$n=115$ patients

Results are given as the mean (SD)

CSA cross sectional area, ANOVA analysis of variance, BCTQ Boston Carpal Tunnel Questionnaire, NCS nerve conduction studies, DML distal motor latency, US ultrasonography, SCV sensory conduction velocity

ANOVA for repeated measurements-diagnostic effect: US $(p=0.135), \operatorname{NCS}(p=0.059)$

ANOVA for repeated measures-effect of surgical treatment: US $(p<0.001)$, NCS $(p<0.001)$

ANOVA for repeated measurements-effect of interaction between diagnosis and surgical treatment: US $(p=0.990)$, NCS $(p=0.246)$

compression syndrome, cervical radiculopathy or even to an advanced degree of CTS [22]. The evaluation of the patients who did not obtain remission of paresthesia after 4 months of the surgical treatment was based on clinical criteria, using the parameters to the CTS- 6 and secondly BCTQ $[1,5,24]$. Though the false-negative patients had normal (absent) results for STC by US and NCS in this study, they were submitted to surgical treatment, supported by the results obtained by the clinical diagnosis for CTS in the initial clinical evaluation. Patients with normal results (absent) for CTS by the US showed better performance in the remission of paresthesia after surgical treatment, as shown in the Table 1. To obtain good quality of evidence in this accuracy study, the degree of CTS impairment provided by US and NCS was discarded and reduced to a simple dichotomous (present / absent, abnormal / normal) diagnosis to make these tests useful in clinical practice of routine $[8,9,11]$. The parameters and cut-off points considered in this study for the diagnosis of CTS by the US and NCS had a direct impact on the primary and secondary outcomes, producing the four possible types of results of a diagnostic test, showing balanced results for the values of accuracy, especially between sensitivity and specificity. The positive results obtained by the kappa index in the evaluation of NCS and US concordance in relation to the reference standard in this study expressed the reliability of these tests for the diagnosis of CTS, with NCS showing a better performance. Mondelli et al. evaluated the diagnostic usefulness of US and NCS in patients with a clinical diagnosis of CTS and obtained positive kappa values with good concordance [19]. The confirmation of the clinical diagnosis of CTS in $90.4 \%$ of patients, with a total of $84.3 \%$ for NCS and $78.3 \%$ for the USusing remission of paresthesia as the reference standard-validated the CTS- 6 clinical diagnostic probability instrument used during the initial clinical evaluation. Fowler et al. compared US and NCS using CTS- 6 as a reference standard and obtained results relative to confirmation of the clinical diagnosis of CTS in $65 \%$ of patients, relative to US diagnosis in $61 \%$, and relative to NCS diagnosis in 65\% [29].

The sensitivity, specificity, and positive predictive value of the US and NCS obtained in the current study were similar, showing that both diagnostic methods were effective for diagnosing CTS, with good sensitivity. Well-designed diagnostic accuracy studies with STARD-

Table 5 BCTQ scores for functional status scale relative to CTS diagnosis by US and NCS

\begin{tabular}{llll}
\hline Parameter & After treatment & Before treatment & Difference between after and before treatment \\
\hline US & & & \\
CSA $\geq 10 \mathrm{~mm}^{2}$ (presence) & $2.0(0.9)$ & $3.6(0.9)$ & $-1.6(1.1)$ \\
$\mathrm{CSA}<10 \mathrm{~mm}^{2}$ (absence) & $2.1(0.9)$ & $3.6(1.0)$ & $-1.5(1.1)$ \\
$\mathrm{NCS}$ & & & \\
$\mathrm{SCV}<50 \mathrm{~m} / \mathrm{s}$ and $\mathrm{DML} \geq 4.2 \mathrm{~ms}$ (presence) & $2.0(0.9)$ & $3.6(0.9)$ & $-1.6(1.1)$ \\
$\mathrm{SCV} \geq 50 \mathrm{~m} / \mathrm{s}$ and $\mathrm{DML}<4.2 \mathrm{~ms}$ (absence) & $2.3(0.9)$ & $3.7(0.8)$ & $-1.5(1.1)$ \\
\hline
\end{tabular}

$n=115$ patients

Results are given as the mean (SD)

CSA cross sectional area, ANOVA analysis of variance, BCTQ Boston Carpal Tunnel Questionnaire, NCS nerve conduction studies, DML distal motor latency, US ultrasonography, SCV sensory conduction velocity

ANOVA for repeated measurements-diagnostic effect: US $(p=0.634), \mathrm{NCS}(p=0.821)$

ANOVA for repeated measures-effect of surgical treatment: US $(p<0.001)$, NCS $(p<0.001)$

ANOVA for repeated measures-effect of interaction between diagnosis and surgical treatment: US $(p=0.629)$, NCS $(p=0.622)$ 


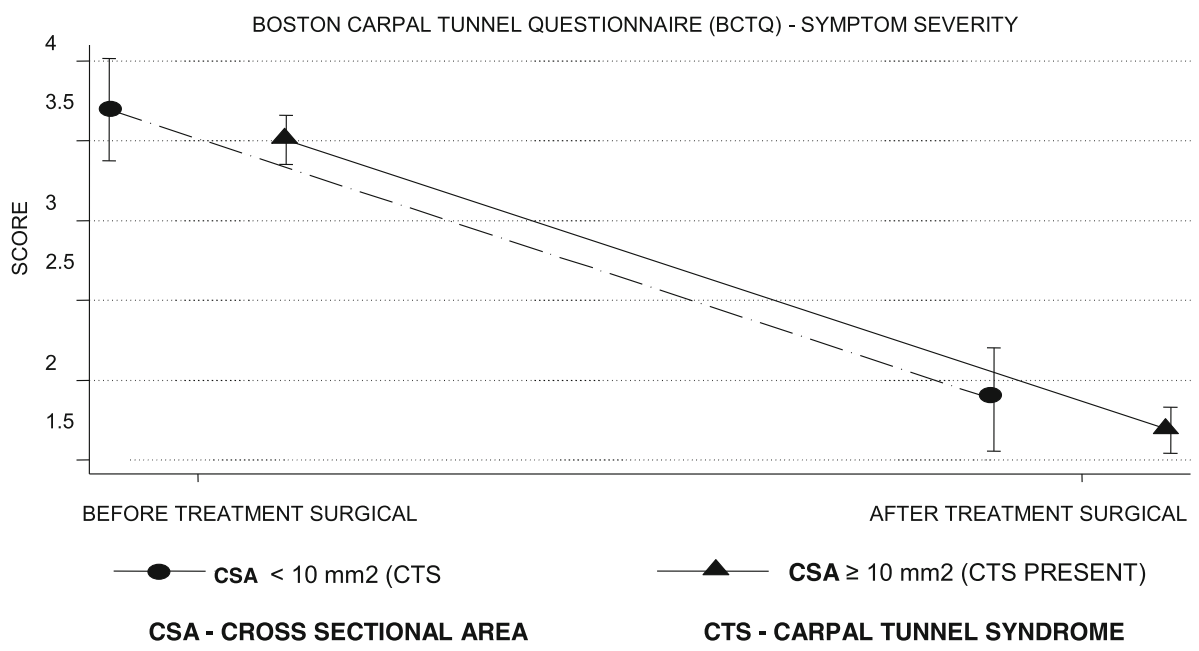

Fig. 6 Evolution of the BCTQ score averages for symptom severity scale by the ultrasonography

compliant methodology obtained similar results when comparing US and NCS $[15,29,30]$. Because of the low negative predictive values, however, neither US nor NCS could adequately rule out the clinical suspicion of CTS in this study when compared with other studies with different reference standards [3, 29-32].

The reduced average of the two scores obtained with the second BCTQ were statistically significant in the current study, indicating improvement of the paresthesia. Thus, the results of the surgical treatment in this study were effective, according to the minimal clinical difference proposed by Ozer et al. [33].

The main limitation of this study was that we did not consider the degree of severity of the initial clinical and complementary diagnosis of CTS. The two-point discrimination test and atrophy of the thenar musculature used in the CTS- 6 model are directly linked to the severity of CTS [34]. A value of $>13 \mathrm{~mm} 2$ for the median nerve area found during US would correspond to a moderate degree of impairment $[35,36]$. Absence of a
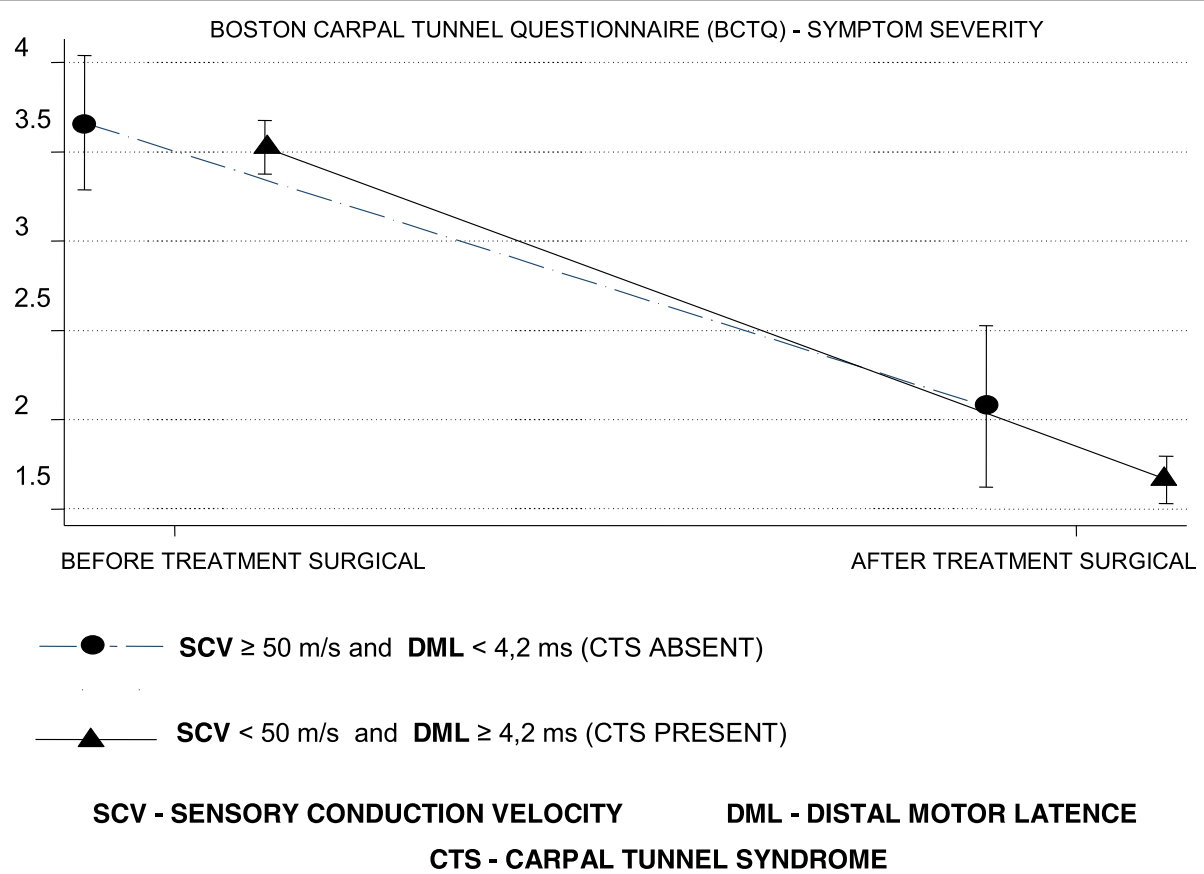

Fig. 7 Evolution of the BCTQ score averages for symptom severity by nerve conduction studies 


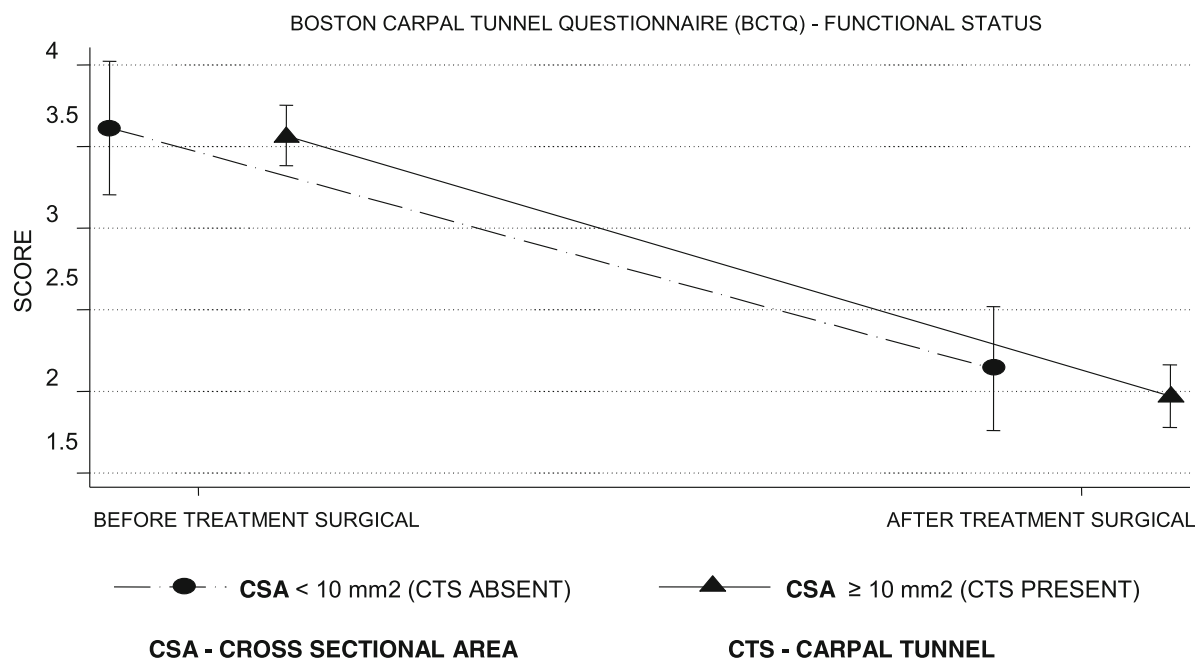

Fig. 8 Evolution of the mean BCTQ scores for functional status by the ultrasonograph

sensory response and abnormal distal motor latency during NCS would correspond to a severe degree of impairment $[3,19]$.

Another limitation of this study was the inclusion of only female patients, having the disadvantage of limiting the generalization capacity of available information [10].

\section{Conclusions}

US and NCS were effective in the diagnosis of CTS, showing a good sensitivity for the detection of patients with CTS. The US and NCS did not show adequate complementary exams to avoid the clinical suspicion of CTS. The NCS presented better concordance regarding the reference standard (remission of paresthesia) than the US. The CTS- 6 clinical diagnostic probability instrument was effective and validated for the suspected cases of CTS, through the results obtained by the reduction of the means of the scores at the postoperative in relation to the preoperative evaluated by the BCTQ. The conclusions obtained by study will be useful for areas that routinely handle the diagnosis-treatment algorithm of CTS such as rheumatology, neurology, neurosurgery and orthopedics. This accuracy clinical trial provided further data regarding clinical diagnosis and surgical treatment that may be useful in future research.
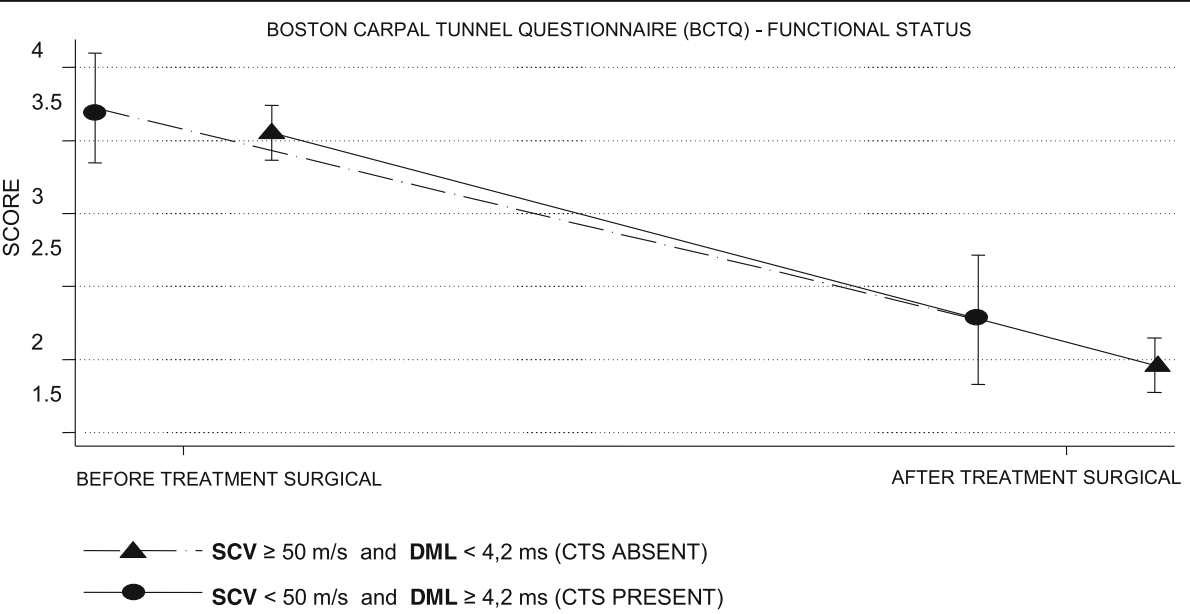


\section{Additional files}

Additional file 1: Table S6. Clinical diagnostic probability instrument CTS-6. (DOCX $17 \mathrm{~kb}$ )

Additional file 2: Table S7. Distribution of patients by clinical characteristics. (DOCX $17 \mathrm{~kb}$ )

Additional file 3: Table S8. Distribution of patients in percentages of CTS diagnosis for US, NCS and reference standard. (DOCX $14 \mathrm{~kb}$ )

Additional file 4: Table S9. Sensitivity and specificity of the US in relation to the reference standard. (DOCX $14 \mathrm{~kb}$ )

Additional file 5: Table S10. Sensitivity and Specificity of the NCS in relation to the reference standard. (DOCX $14 \mathrm{~kb}$ )

Additional file 6: Table S11. Positive and negative predictive value of the US in relation to the reference standard. (DOCX $14 \mathrm{~kb}$ )

Additional file 7: Table S12. Positive and negative predictive value of the NCS in relation to the reference standard. (DOCX $14 \mathrm{~kb}$ )

Additional file 8: Table S13. Positive and negative likelihood ratios of US in relation to the reference standard. (DOCX $14 \mathrm{~kb}$ )

Additional file 9: Table S14. Positive and negative likelihood ratios of the NCS in relation to the reference standard. (DOCX $14 \mathrm{~kb}$ )

\section{Abbreviations}

BCTQ: Boston carpal tunnel questionnaire; CSA: Cross sectional area; CTS: Carpal tunnel syndrome; CTS-6: Instrument of probability diagnostic for carpal tunnel syndrome; DML: Distal motor latency; NCS: Nerve conduction studies; SCV: Sensory conduction velocity; STARD: Standards for reporting of diagnostic accuracy studies; US: Ultrasonography

\section{Acknowledgements}

The authors thank Drs Marcel Saiji Takeshita and Ruschansky Vilela de Azevedo for their friendship, confidence and valuable time spent on the US and NCS examinations, respectively, of the patients who participated in this study. The authors thank all colleagues, residents, and staff of the Department of Orthopedics and Traumatology, Federal University of São Paulo/Paulista School of Medicine and Discipline of Orthopedics and Traumatology, Paraiba Valley Regional Hospital and Taubaté University Hospital, University of Taubaté for their collaboration, care, and support. We thanks Nancy Schatken, BS, MT (ASCP), from Edanz Group

(global@edanzediting.com) for editing a draft of this manuscript.

\section{Funding}

The authors declare that they have no funding for this study.

\section{Availability of data and materials}

Although all relevant data are included in this manuscript. Additional data and datasets used and/or analyzed during the current study are available from the corresponding author upon reasonable request.

\section{Authors' contributions}

BFRP: developed the study protocol and contributed to put into practice the design of the study and its methodology, being the main investigator of this clinical trial. FF: participated in the design of the study and actively collaborated in the review and orientation of this clinical trial; MJST collaborated in the correction and revision of this clinical trial; JCB: was the founder of the study design and the main coordinator of this clinical trial, was responsible given final approval of the version to be published. All authors contributed to the improvement of this study and approved the final manuscript.

\section{Ethics approval and consent to participate}

The Ethics and Research Committees of Federal University of São Paulo/ Paulista School of Medicine, São Paulo, São Paulo State, Brazil (approval No. 244468) on 12 April 2013 and Paraiba Valley Regional Hospital and Taubaté University Hospital, University of Taubaté, Taubaté, São Paulo State, Brazil (No. 009/13) on 18 June 2013 approved this study. We have obtained the written informed consent for participation in the study from all participants.

\section{Competing interests}

The authors declare that they have no competing interests.

\section{Publisher's Note}

Springer Nature remains neutral with regard to jurisdictional claims in published maps and institutional affiliations.

\section{Author details}

${ }^{1}$ Division of Hand Surgery and Upper Limb, Discipline of Orthopaedics and Traumatology, Paraiba Valley Regional Hospital and Taubaté University Hospital, University of Taubaté, 239 Francisco de Barros, Taubaté, São Paulo zip code 12020-230, Brazil. Division of Hand Surgery and Upper Limb, Department of Orthopedics and Traumatology, Federal University of São Paulo, Paulista School of Medicine, 786 Borges Lagoa, São Paulo, São Paulo zip code 04038-030, Brazil.

Received: 3 October 2017 Accepted: 4 April 2018

Published online: 12 April 2018

\section{References}

1. Kwon BC, Jung Kl, Baek GH. Comparison of sonography and electrodiagnostic testing in the diagnosis of carpal tunnel syndrome. J Hand Surg Am. 2008:33:65-71.

2. Bickel KD. Carpal tunnel syndrome. J Hand SurgAm. 2010;35:147-52.

3. El Miedany YM, Aty SA, Ashour S. Ultrasonography versus nerve conduction study in patients with carpal tunnel syndrome: substantive or complementary tests? Rheumatology (Oxford). 2004:43:887-95.

4. Pimentel $B F$, Abicalaf $C A$, Braga $L$, et al. Cross-sectional area of the median nerve characterized by ultrasound in patients with carpal tunnel syndrome before and after release of the transverse carpal ligament. J Diagn Med Sonography. 2013;29:116-21.

5. Graham B, Regehr G, Naglie G, et al. Development and validation of diagnostic criteria for carpal tunnel syndrome. J Hand Surg Am. 2006;31: 919-24.

6. Prime SM, Palmer J, Khan WS, et al. Is there light at the end of the tunnel? Controversies in the diagnosis and management of carpal tunnel syndrome. Hand (NY). 2010;5:354-60.

7. Scott IA, Glasziou PP. Improving effectiveness of clinical medicine: the need for better translation of science into practice. Med J Aust. 2012;197:374-8.

8. Rutjes AW, Reitsma JB, Coomarasamy A, et al. Evaluation of diagnostic tests when there is no gold standard: a review of methods. Health Technol Assess 2007;11:iii, ix-51.

9. McCabe SJ. Diagnosis of carpal tunnel syndrome. J Hand Surg Am. 2010;35: 646-8.

10. Boyer K, Wies J, Turkelson CM. Effects of bias on the results of diagnostic studies of carpal tunnel syndrome. J Hand Surg Am. 2009;34:1006-13.

11. Bossuyt PM, Reistma JB, Bruns DE, et al. STARD 2015: an updated list of essential items for reporting diagnostic accuracy studies. BMJ. 2015;351: h5527.

12. Sernik RA, Abicalaf CA, Pimentel BF, et al. Ultrasound features of carpal tunnel syndrome: a prospective case-control study. Skelet Radiol. 2008;37: $49-53$.

13. Duncan I, Sullivan P, Lomas F. Sonography in the diagnosis of carpal tunnel syndrome. AJR Am J Roentgenol. 1999:173:681-4.

14. Martinoli C, Bianchi S, Gandolfo N, et al. US of nerve entrapments in osteofibrous tunnels of the upper and lower limbs. Radiographics 2000; 20(Spec No):S199-S213; discussion S213-7.

15. Visser $\mathrm{LH}$, Smidt MH, Lee ML. High-resolution sonography versus EMG in the diagnosis of carpal tunnel syndrome. J Neurol Neurosurg Psychiatry. 2008; 79:63-7.

16. Werner RA, Andary M. Electrodiagnostic evaluation of carpal tunnel syndrome. Muscle Nerve. 2011:44:597-607.

17. Padua L, Lo Monaco M, Padua R, et al. Neurophysiological classification of carpal tunnel syndrome: assessment of 600 symptomatic hands. Ital J Neurol Sci. 1997:18:145-50

18. Jablecki CK, Andary MT, Floeter MK, et al. Practice parameter: electrodiagnostic studies in carpal tunnel syndrome. Report of the American Association of Electrodiagnostic Medicine, American Academy of Neurology, and American Academy of physical medicine and rehabilitation. Neurology. 2002:58:589-92. 
19. Mondelli M, Filippou G, Gallo A, et al. Diagnostic utility of ultrasonography versus nerve conduction studies in mild carpal tunnel syndrome. Arthritis Rheum. 2008;59:357-66.

20. Ntani G, Palmer KT, Linaker C, et al. Symptoms, signs and nerve conduction velocities in patients with suspected carpal tunnel syndrome. BMC Musculoskelet Disord. 2013;14:242.

21. Brill S, Middleton W, Brill G, et al. Bier's block: 100 years old and still going strong! Acta Anaesthesiol Scand. 2004;48:117-22

22. Rodner CM, Katarincic J. Open carpal tunnel release. Tech Orthopaedics. 2006;21:3-11.

23. Louie D, Earp B, Blazar P. Long-term outcomes of carpal tunnel release: a critical review of the literature. Hand (NY). 2012;7:242-6.

24. Levine DW, Simmons BP, Koris MJ, et al. A self-administered questionnaire for the assessment of severity of symptoms and functional status in carpal tunnel syndrome. J Bone Joint Surg Am. 1993;75:1585-92.

25. De Campos CC, Manzano GM, De Andrade LB, Castelo FILHOA, Nóbrega JA. Translation and validation of an instrument for evaluation of severity of symptoms and the functional status in carpal tunnel syndrome. Arq Neuropsiquiatr. 2003;61:51-5. (in Portuguese)

26. Machin D, Campbell MJ, Tan SB, et al. Sample size tables for clinical trials. 3rd ed. Wiley-Blackwell: Chichester, UK; 2009

27. Alfonso C, Jann $S$, Massa $R$, et al. Diagnosis, treatment and follow-up of the carpal tunnel syndrome: a review. Neurol Sci. 2010;31:243-52.

28. Louie DL, Earp BE, Collins JE, Losina E, Katz JN, Black EM, Simmons BP, Blazar PE. Outcomes of carpal tunnel release at a minimum of ten years. J Bone Joint Surg Am. 2013:95(12):1067-73.

29. Fowler JR, Munsch M, Tosti R, et al. Comparison of ultrasound and electrodiagnostic testing for diagnosis of carpal tunnel syndrome: study using a validated clinical tool as the reference standard. J Bone Joint Surg Am. 2014;96:e148.

30. Fowler JR, Cipolli W, Hanson T. A comparison of three diagnostic tests for carpal tunnel syndrome using latent class analysis. J Bone Joint Surg Am. 2015:97:1958-61

31. Taylor-Gjevre RM, Gjevre JA, Nair B. Suspect carpal tunnel syndrome: do nerve conduction study results and symptoms match? Can Fam Physician 2010;56:e250-4.

32. Pastare $D$, Therimadasamy AK, Lee $E$, et al. Sonography versus nerve conduction studies in patients referred with a clinical diagnosis of carpal tunnel syndrome. J Clin Ultrasound. 2009:37:389-93.

33. Ozer K, Malay S, Toker S, et al. Minimal clinically important difference of carpal tunnel release in diabetic and nondiabetic patients. Plast Reconstr Surg. 2013;131:1279-85.

34. D'Arcy CA, McGee $\mathrm{S}$. The rational clinical examination: does this patient have carpal tunnel syndrome? JAMA. 2000;283:3110-7.

35. Karadağ YS, Karadağ O, Ciçekli E, et al. Severity of carpal tunnel syndrome assessed with high frequency ultrasonography. Rheumato Int. 2010;30:761-5.

36. Ghasemi M, Abrishamchi F, Basiri K, et al. Can we define severity of carpal tunnel syndrome by ultrasound. Adv Biomed Res. 2015;4:138.

\section{Ready to submit your research? Choose BMC and benefit from:}

- fast, convenient online submission

- thorough peer review by experienced researchers in your field

- rapid publication on acceptance

- support for research data, including large and complex data types

- gold Open Access which fosters wider collaboration and increased citations

- maximum visibility for your research: over $100 \mathrm{M}$ website views per year

At BMC, research is always in progress.

Learn more biomedcentral.com/submissions 